\title{
Research on Marketing Strategies of Different Movies and Film Market
}

\author{
Ye Chen
}

\author{
Zhejiang Gongshang University \\ 1299129530@qq.com
}

\begin{abstract}
With economic development and the improvement of people's living standards, the service industry, especially the film industry, develops and expands. In recent years, with the progress of the Chinese film market, film marketing strategies become an important factor in the success of films. This article mainly analyzes the current development of the film market by using the PEST model, the marketing strategies and results of different films. Finally, it summarizes the factors that affect the quality of film marketing. The research method is mainly through the collection of relevant literature and data to investigate the Chinese film market and specific films. Through research, it is found that the Chinese film market is in a stage of gradual development, the audience shows a younger trend. Movies that rely solely on celebrity traffic are no longer popular and the reputation of film is becoming increasingly important.
\end{abstract}

Keywords: movie marketing strategy, PEST model, film market development, Word of mouth and quality.

\section{INTRODUCTION}

With the improvement of Chinese people's living standard, more and more people are willing to spend money on entertainment industry. Therefore, the Chinese film market has gradually developed in this situation. Besides, domestic films rise and occupy most of the box office and there have been a lot of word-of-mouth and box office hits. At the same time, film themes, production and publicity methods are becoming more and more diversified. Besides, different movies have different marketing strategies to attract audience. Hence, a good marketing strategy of a movie is very important for its success. There are also some literature on film marketing strategies in this field at present, but most of them do not conduct much comparative study. The topic of this paper is to study the different results brought about by the marketing strategies of different films. The specific problems of the study are how to develop a good publicity strategy, what are the results and causes of different marketing strategies for the same type of movies. Based on this study, filmmakers and promoters can know how to make a movie more successful. In this paper, the author mainly uses the secondary data and references for research.

\section{ANALYSIS OF MOVIE MARKET BASED ON PEST MODEL}

The PEST model is a powerful tool for analyzing strategic risks. It recognizes the changes and influence of the external macro environment on the competitive position of the enterprise. [1] It also applies to industry analysis. Therefore, the paper analyzes the film industry from the four aspects of the PEST model.

\subsection{Political}

In recent years, Chinese film industry develops rapidly, which is inseparable from the strong support of the State Council and local governments. The Chinese government repeatedly issues documents to promote the development of the film industry. Then, the article lists the policies of some provinces and cities to support the healthy improvement of the film industry.

Bejing: Establish a film and television publication creation fund; improve the subsidy policy for the construction of multi-hall theaters; introduce a special fund policy for the development of the film industry, etc.

Shanghai: Increase financial support for Shanghai film companies; strengthen the construction of Shanghai film talent team, etc. 
Zhejiang: Optimize the film and television management system; improve the film and television development environment; strive for greater financial support; implement high-end film and new media talent training programs, etc.

The policies of the above three places, including many other regions in China, reflect a clear attitude towards the development of the film industry. At the same time, major urban agglomerations and economic belts work together. And many places are competing to build "Oriental Hollywood". All these phenomena show that the current Chinese film market is strongly supported by policies.

\subsection{Economical}

Economic factors are critical to the evaluation of the film market. The paper lists some economic indicators that help this analysis.

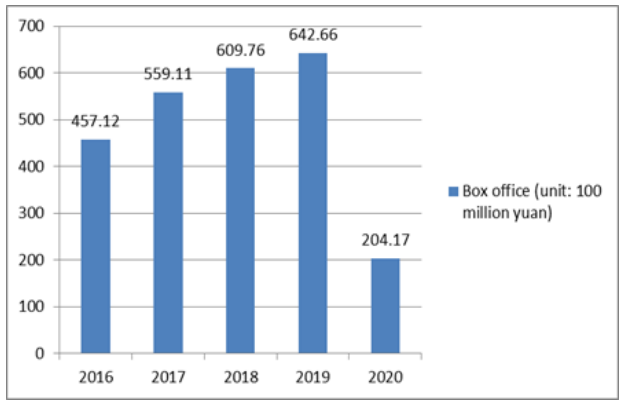

Figure 1. Annual gross box office of the Chinese film market

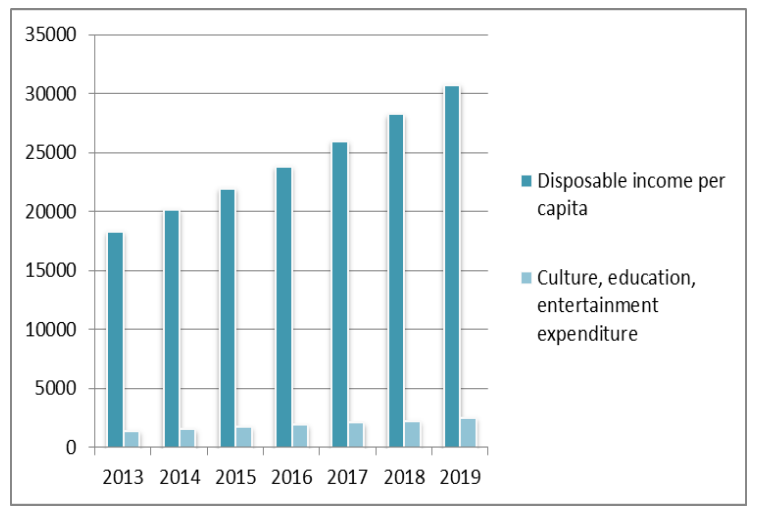

Figure 2. Resident income and expenditure information

According to figure 1, from 2016 to 2019, the box office of the Chinese film market increased from 45.712 billion to 64.266 billion and the trend was stable. The epidemic was the main reason for the sharp drop in box office in 2020. From the figure 2, it can be found that the income level of Chinese residents increases in recent years, and the expenditure on culture, education and entertainment had gradually grow. From 2013 to 2019 , the average growth rate of per capita disposable income of residents was $9.015 \%$ (the growth rate refers to the ratio of the difference between the values of two consecutive years to the value of the previous year). Also the scale of the movie market gets larger these years.

\subsection{Social}

The article analyzes the population distribution, education situation and age structure of people viewing movies to acquire the information on social factor.

Table 1. Regional population (Unit: ten thousand people)

\begin{tabular}{|c|c|c|c|c|c|c|c|}
\hline region & Beijing & Shanghai & Hebei & Shandong. & Guangdong. & Jiangsu & Henan \\
\hline 2017 & 2171 & 2418 & 7520 & 10006 & 11169 & 8029 & 9559 \\
\hline 2018 & 2154 & 2424 & 7556 & 10047 & 11346 & 8051 & 9605 \\
\hline 2019 & 2154 & 2428 & 7592 & 10070 & 11521 & 8070 & 9640 \\
\hline
\end{tabular}

Table 2. A sample survey of the population with bachelor degree and above in regions (Year: 2019, Unit:people)

region Beijing Shanghai Shandong Jiangsu Guangdong Sichuan Zhejiang

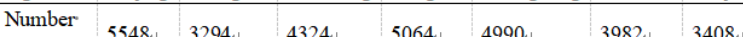
of people

The above data enumerates the seven regions with larger populations and the seven regions with higher education levels in China. The population of these areas is relatively stable, always occupying about $36.7 \%$ of China's total population. In the total sample, the number of people with a bachelor's degree or above is 70,224, which means that the number of people with the same level in the above-mentioned regions accounted for $43.59 \%$ of the total. The author finds that these areas have a high degree of overlap. It is foreseeable that these places will be the main areas for film consumption.

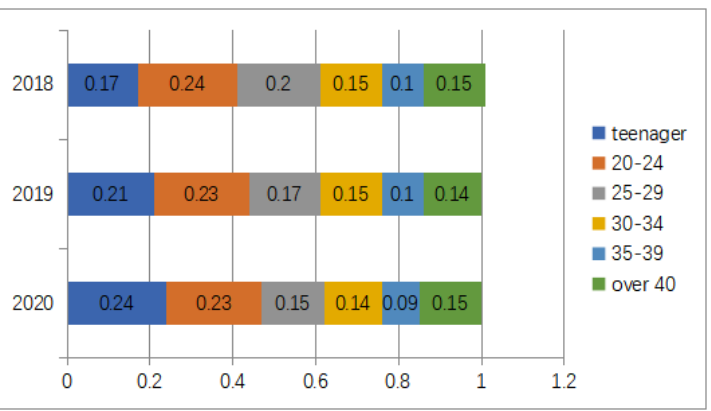

Figure 3. Age distribution of movie viewers

Through the chart, it is found that the audience shows a younger trend in recent years. From 2018 to 2020, the population with the biggest change in the proportion was teenagers and the percentage rose by $7 \%$. The proportion of viewers aged 25-29 dropped significantly. Therefore, film marketing should pay more attention to the promotion of young people.

\subsection{Technological}

Nowadays, no one will underestimate technology. And some new technologies and equipment are changing the way the content of film and television media. 
The following are two technologies that may have an impact on future industrial development.

The first is the combination of $5 \mathrm{G}$ and VR. What $5 \mathrm{G}$ changes is every link in the information dissemination chain, and it will affect all mobile Internet applications and businesses moving towards the "video" trend. The second is the application of long video. Long video provides many strategic advantages for the brand. It creates an emotional connection with the audience by telling stories. And help find potential customers.

\subsection{Summary of the PEST model}

Among the above four factors, economic factor has the greatest impact on the film market because it is the most basic and decisive factor. The film industry as a cultural and entertainment industry, the consumer is always the subject. Whether the audience pays for a movie is a key indicator that determines the success of the movie. And the economic power of consumers determines their choice of watching movies, including whether to watch movies, what movies to watch, etc. More people will watch movies only when their living standards and economic conditions improve, which will meanwhile promote the prosperity and development of the film industry. These four factors also influence each other at the same time. Policy guidance needs to be in line with local economic development and social factors including customs. In addition, the improvement of the economic level will also promote the progress of technology which incorporates digital film, high resolution, sound improvement and IMAX technology, etc.

It is inevitable that these factors may also have some negative impact. For example, the formulation of policies does not apply to the development of the film market or the traditional concepts and habits in some regions make it difficult for people to accept new film formats. And the imbalance of regional economic development also affects the improvement of the film market. Therefore, through the analysis of the film industry in four aspects: policy, economy, society, and technology, it should be considered how to expand the positive impact and reduce the negative impact.

\section{ANALYSIS OF MARKETING}

After analyzing the film market by PEST model, this article researches two specific films' marketing strategies. The two films are of the same type but there is a big gap in box office and word-of-mouth.

\subsection{The Wandering Earth}

The film was released in mainland China on February 5, 2019. As China's first science fiction film, it has produced huge market revenue that the total box office was 4.655 billion yuan. Obviously film marketing strategy plays a key role there.

The film focuses on content promotion and makes full use of value of intellectual property. Thousands of props, conceptual designs, drawings and special effects are used in this film, which is full of sense of technology. In addition to technological elements, the film also adds many emotional elements. Such as family affection, heroic feelings, national pride, international cooperation concept, etc. And there are many humorous plots. Compared with other disaster films, "The Wandering Earth" has elevated science fiction to national sentiments such as love for the country and the earth. Taking the earth to travel through the universe and taking home together is a unique Chinese homeland romance. And this happened to hit the hearts of the audience, and it was also a distinctive feature of this movie. Besides, the film is adapted from the novel of the same name by the famous science fiction writer Liu Cixin. "Three-Body" won the Hugo Award, making Liu Cixin the spokesperson of Chinese science fiction literature. With the changes in the earth's ecology, the development of science and technology and the exploration of the vast universe by mankind, Liu Cixin's science fiction world gradually became popular. So "The Wandering Earth" is already excellent in the plot. Many book fans are also attracted by the film publicity.

Appropriate release time. The film was released in the Spring Festival of 2019. During this period, light comedy films always occupied a dominant position. "The wandering earth" provides different choices for the audience. The Spring Festival is a festival for the reunion of the whole country, and it is also the most intense time for people to feel homesick. "The Wandering Earth" captures this point. Not only does the movie's plot be set at the Spring Festival, some lively Spring Festival scenes frequently appear in it, and the word "go home" often appears in the film. In marketing, family affection is naturally the main topic of "Wandering Earth". In addition to publishing related topics and activities in the media, a series of family love posters are also released in conjunction with the Spring Festival and returning home in the early stage of the publicity process. Finally, combined with the movie content, a "home theme" poster is launched, calling for family members to watch the movie. At the same time, the film uses different strategies for different groups. For example, for science fiction fans, they publicize the elements of film science and technology, and for other audiences, they take family affection and family as the starting point.

Multi-channel promotion and topic creation. The film producer publicizes with the help of mass media and uses Micro-Blog, Tik Tok and other platforms to create related topics. The promotion on various social media gives people a feeling that the movie is ubiqui- 
tous. Users are surrounded by continuous topics, and each topic is constantly improving consumers' motivation to watch movies. Also the producer carries out offline publicity activities, such as the National University roadshow. Therefore, it attracted a large number of young audiences.[4]

\subsection{Shanghai Fortress}

Inappropriate promotional content. The film focuses on the promotion of stars. And the film was promoted as the second Chinese sci-fi blockbuster after "The Wandering Earth", which created high expectations for movie fans. However, the film quality cannot be compared with it. The psychological gap of the audience directly led to the decline in the reputation of the film.

Incorrect casting and screening time. Although the film is classified as a science fiction film, it actually mainly shows the emotional story of the character. Besides, the impression of the actors and actresses on the audience does not match the roles of the film. Due to the success of "The Wandering Earth", the audience's demand for science fiction movies has increased. This film was chosen to be released shortly after "The Wandering Earth" so it is quite difficult to meet the requirements of the public.[5]

\section{CONCLUSION}

In recent years, the audience show a younger trend. Therefore, grasping the preferences of young people is a key factor in the success of the film.

The word-of-mouth effect of the movie is greater than the celebrity effect. So movie quality is very important.

People choose an appropriate release time according to the genre and characteristics of the movie, and the promotional content needs to be consistent with the movie itself.

This article mainly uses second-hand data and literature for research, and the factors that affect the quality of the marketing strategy are not comprehensive. The improvement method is: Combining actual data and comparing more different types of film marketing strategies to obtain more accurate film market analysis results. According to the third conclusion, the further study should focus on time, genre and promotional content more. For example, a good strategy needs to choose the release time and produce promotional content according to the movie theme, and make targeted publicity for different kinds of audience.

\section{REFERENCES}

[1] Sammut-Bonnici T, Galea D. PEST analysis[J]. 2014.

[2] Wilcox B. Current trends in the marketing and promotion of movies using social media[J]. 2012.

[3] Cooper-Martin E. Consumers and movies: Some findings on experiential products[J]. ACR North American Advances, 1991.

[4] Li Xiuhui. Analyze the film marketing strategy based on the 4P theory-take the movie "The Wandering Earth" as an example [J]. News Research Guide, 2021, 12(02): 162-163.

[5] Wang Ting,Li Yexin.The impact of word-of-mouth marketing on the box office of IP movies: Taking "The Wandering Earth" and "Shanghai Fortress" as examples[J].Journalist Observation,2020(14):134

[6] Huang Chuxin,Wen Chuanjun.On the marketing strategy of film and television dramas under the new media environment $[\mathrm{J}]$. News Forum,2019(06):19-22. 